\title{
Estudo comparativo do resfriamento de laranja valência, em três sistemas de resfriamento
}

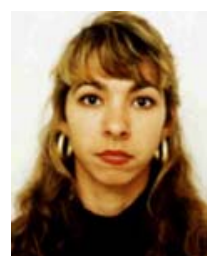

Bárbara Teruel ${ }^{1}$, Luís Cortez ${ }^{2} \&$ Lincoln N. Fo ${ }^{3}$

\begin{abstract}
1 FEM/UNICAMP, CP 6122, CEP 13001-970, Campinas, SP. Fone (19) 3788-3262. E-mail: barbara@fem.unicamp.br (Foto) 2 FEAGRI/UNICAMP, CP 6011, CEP 13001-970, Campinas, SP. Fone (19) 3788-1033. E-mail: cortez@agr.unicamp.br ${ }^{3}$ FEA/UNICAMP, CP 6121, CEP 13001-970, Campinas, SP. E-mail: neveslin@ceres.fea.unicamp.br
\end{abstract}

Protocolo $053-24 / 4 / 2001$

\begin{abstract}
Resumo: Este trabalho apresenta um estudo com o qual se pretende comparar o resfriamento de laranja Valência (Citrus Sinensis Osbeck) em três sistemas: ar forçado, água gelada e em câmara de estocagem convencional. O sistema de resfriamento com ar forçado operou com um fluxo de ar de $1933 \mathrm{~m}^{3} \mathrm{~h}^{-1}$, a $1^{\circ} \mathrm{C}$ e umidade relativa (UR) de $88,4 \% \pm 2,0$, com velocidade do ar em torno de $1 \mathrm{~m} \mathrm{~s}^{-1}$. Nos experimentos com água gelada foi utilizado um sistema de imersão, com capacidade de $0,23 \mathrm{~m}^{3}$ de água, a $1^{\circ} \mathrm{C}$. A câmara de resfriamento utilizada tinha capacidade de $2,90 \mathrm{~J} \mathrm{~s}^{-1}$. O tempo de meio e de sete oitavos do resfriamento foi determinado partindo-se das leituras da temperatura no centro dos frutos, com duas repetições. O resfriamento do leito de frutos com ar forçado não se mostrou homogêneo, obtendo-se tempos que variaram de 107 a $170 \mathrm{~min}$, dependendo da posição do fruto no interior da embalagem. No sistema com água gelada o resfriamento acontece uniformemente em todo o leito de frutos, sendo o tempo médio de resfriamento de $57 \mathrm{~min}$. Quando os frutos foram resfriados no sistema convencional, o tempo de resfriamento oscilou de 362 e 460 min, oito vezes maior que o obtido com água e três vezes maior com ar forçado.
\end{abstract}

Palavras-chave: refrigeração, tempo de resfriamento, resfriamento rápido

\section{A comparative study of the cooling of oranges using three cooling systems}

\begin{abstract}
This work presents a study to compare the cooling of oranges with room cooling, forced-air cooling and hydrocooling systems of the Valência orange (Citrus Sinensis Osbeck). The forced-air cooling system operated with an air flow of $1933 \mathrm{~m}^{3} \mathrm{~h}^{-1}$, at $1^{\circ} \mathrm{C}$, relative humidity $(\mathrm{RH})$ of $88.4 \% \pm 2.0$ and air velocity around $1 \mathrm{~m} \mathrm{~s}^{-1}$. In the experiments with cold water an immersion hydrocooling system with a capacity of $0.23 \mathrm{~m}^{3}$ of water was used at a temperature of $1^{\circ} \mathrm{C}$, approximately. The half cooling time and seven-eighths cooling time were determined from the temperature data, with two replications. The results showed that the cooling of the bed fruits with forced air is not homogeneous, obtaining a mean between 107 a 170 min, depending on the position of the fruit in the package. In the hydrocooling system, the cooling of the fruits occurs uniformly in the bed, with a mean cooling time of $57 \mathrm{~min}$. In room cooling, the time of cooling was 362 and 460 min, eight times that of hydrocooling system and more than three times that of the forced air cooling time.
\end{abstract}

Key words: refrigeration, cooling time, pre-cooling

\section{INTRODUÇÃO}

A diminuição da temperatura até níveis compatíveis com o produto, traz o retardamento da deterioração dos frutos, adiando o desenvolvimento de microrganismos e diminuindo o processo de respiração e de transpiração, os quais são responsáveis pelo rápido amadurecimento e, conseqüentemente, pela perda de qualidade dos frutos.

O tratamento pós-colheita adequado, o que inclui o resfriamento, garante várias vantagens, como: consumo de um produto de melhor qualidade, menores perdas para o comerciante, aumento do tempo de comercialização com menor desperdício, e maiores ganhos (Kader, 1992 e ASHRAE, 1994).

O valor das perdas de produtos frescos no Brasil, dentre eles as frutas, pode chegar a até $50 \%$, dependendo do produto e da época do ano. Dentre as várias causas que originam estas perdas, está a não utilização de armazenamento refrigerado depois da colheita, que mantém os produtos adequadamente resfriados até o momento do consumo (Carraro \& Mancuso, 1994 e IBRAF, 1999). 
A manutenção da temperatura de refrigeração adequada a cada produto, da colheita ao consumo, precisa da implementação de uma "Cadeia do Frio" (CF) adequada. São elementos fundamentais desta cadeia: (a) os sistemas de resfriamento rápido e os sistemas de estocagem; (b) caminhões frigorificados para o transporte terrestre; (c) containers frigoríficos para o transporte marítimo, aéreo ou ferroviário; (d) expositores refrigerados de supermercados; (e) geladeiras domésticas e industriais.

Para realizar o resfriamento rápido depois da colheita, diversos métodos podem ser utilizados, dentre eles o sistema que utiliza ar forçado, e os que empregam água como meio de resfriamento. Por outro lado, as câmaras de resfriamento convencionais devem ser utilizadas apenas para a conservação ou manutenção da temperatura dos produtos que já foram resfriados de forma rápida, devido ao fato de que estas possuem eficiência de resfriamento menor, o que se traduz em tempo de resfriamento maior quando comparado com os outros dois métodos.

Segundo Mitchell et al. (1973) em geral o sistema de circulação forçada de ar promove um resfriamento em um tempo de quatro a dez vezes do tempo exigido em câmaras convencionais, mas ainda é duas a três vezes mais lento que o resfriamento com água gelada. A relação entre o tempo e a temperatura caracteriza a eficiência do resfriamento e, quanto menor for o tempo de resfriamento, maior será a eficiência do sistema, o que se traduz em produtos com vida útil de prateleira maior.

Em vista disso, este trabalho foi desenvolvido com o objetivo de se realizar o resfriamento de laranja Valência, utilizando-se um sistema convencional, um sistema com ar forçado e um de resfriamento por imersão com água, a fim de se comparar as taxas de resfriamento, avaliando-se o tempo de resfriamento.

\section{MATERIAL E MÉTODOS}

\section{Resfriamento com ar forçado}

Um sistema de ar forçado foi montado no interior de uma câmara de refrigeração (Figura 1A). No interior da câmara de resfriamento foi instalado um ventilador centrífugo. $\mathrm{O}$ ventilador succiona $\mathrm{o}$ ar refrigerado que sai do evaporador $\mathrm{e} o$ ar resfriado é forçado a passar transversalmente entre o volume de frutos colocados no túnel de resfriamento o qual está fechado na parte superior e frontal, com uma lona (Figura 1A).

Para o monitoramento da temperatura utilizou-se um sistema de aquisição de dados por computador, o qual consta de um conversor de sinais A/D (7), de uma placa de condicionamento de sinais, e de um computador AT 486.

Para a medição da temperatura no centro das laranjas (variedade Valência) foram inseridos termopares tipo $\mathrm{T}$, os quais foram calibrados previamente $\left( \pm 0,1^{\circ} \mathrm{C}\right)$ e, por sua vez, interligados ao sistema de aquisição de dados. Os termopares foram inseridos em três frutos ao longo da seção transversal do passo do fluxo de ar.

O ponto 1 coincidia com o fruto que estava em maior contato com o fluxo de ar, e o ponto 3 com o que se encontrava mais afastado da entrada do fluxo de ar. O ponto 2 coincide com o fruto na posição central da embalagem. Esses frutos se encontravam na fileira do meio da caixa (Figura 1B).

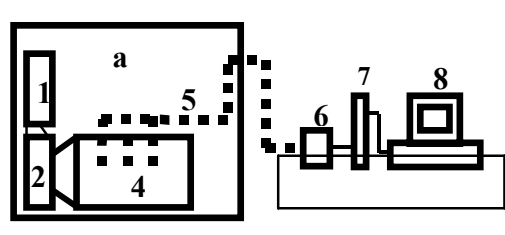

(A)

B1. Evaporador;

2. Ventilador;

3. Duto

4. Volume de caixas com a lona;

5. Termopares;

6. Conversor de sinais;

7. Placa de condicionamento;

8. Computador;

a. Câmara de refrigeração

Figura 1. (A) Elementos que compõem o sistema de resfriamento com ar forçado e (B) Pontos onde foram inseridos os termopares para a medição da temperatura

A temperatura do ar resfriado e insuflado pelo evaporador foi medida e monitorada usando-se um termopar colocado no interior da câmara de resfriamento. A temperatura de ajuste indicada no termostato da câmara de resfriamento foi de $1^{\circ} \mathrm{C}$. Antes do início do experimento, o sistema de resfriamento era ligado até atingir a condição de equilíbrio e, em seguida, eram introduzidas as caixas de frutos.

Para o acondicionamento dos frutos utilizou-se uma embalagem de plástico $(528 \times 335 \times 310 \mathrm{~mm})$ usada comumente para o transporte dos produtos, desde o campo até o galpão de embalagem. Essas caixas possuem aproximadamente $60 \%$ de área de abertura, com $40 \%$ de área livre para a passagem de ar, aproximadamente. Os frutos, depois de pesados e medidos, foram colocados no interior da embalagem em arranjo alternado.

A velocidade do fluxo de ar no interior do túnel de ar forçado foi, em média, de $1,02 \mathrm{~m} \mathrm{~s}^{-1} \pm 0,15$. A taxa de ar passando através dos produtos foi de, aproximadamente, $1933 \mathrm{~m}^{3} \mathrm{~h}^{-1}\left(3 \mathrm{~L} \mathrm{~s}^{-1} \mathrm{~kg}^{-1}\right.$ de produto resfriado).

\section{Resfriamento na câmara convencional}

Para os testes no sistema convencional utilizou-se apenas a câmara de refrigeração (a, na Figura 1A) sem ligar o sistema com ar forçado. Foram usados termopares do tipo T, interligados ao sistema de aquisição de dados (6, 7 e 8 na Figura 1A) para a medição da temperatura no centro dos frutos, do ar de resfriamento e do ar exterior.

Os pontos onde foi medida a temperatura, no interior da embalagem, foram escolhidos aleatoriamente, visto que o ar não segue uma direção preferencial, como acontece quando os frutos são resfriados no túnel com ar forçado.

Inicialmente, a câmara de refrigeração era ligada até atingir a temperatura de $1^{\circ} \mathrm{C}$ e logo em seguida foi introduzida caixa com as laranjas. Os frutos foram acondicionados em arranjo alternado na embalagem de plástico com área efetiva para a circulação do fluxo de ar de $40 \%$. Os testes tiveram duração de $500 \mathrm{~min}$, aproximadamente.

\section{Resfriamento com água gelada}

Utilizou-se um sistema de resfriamento com água por imersão. O sistema de resfriamento (b, na Figura 2A) consta de 
um compressor hermético, um condensador a ar, uma válvula de expansão termostática, um reservatório de líquido e uma bomba.

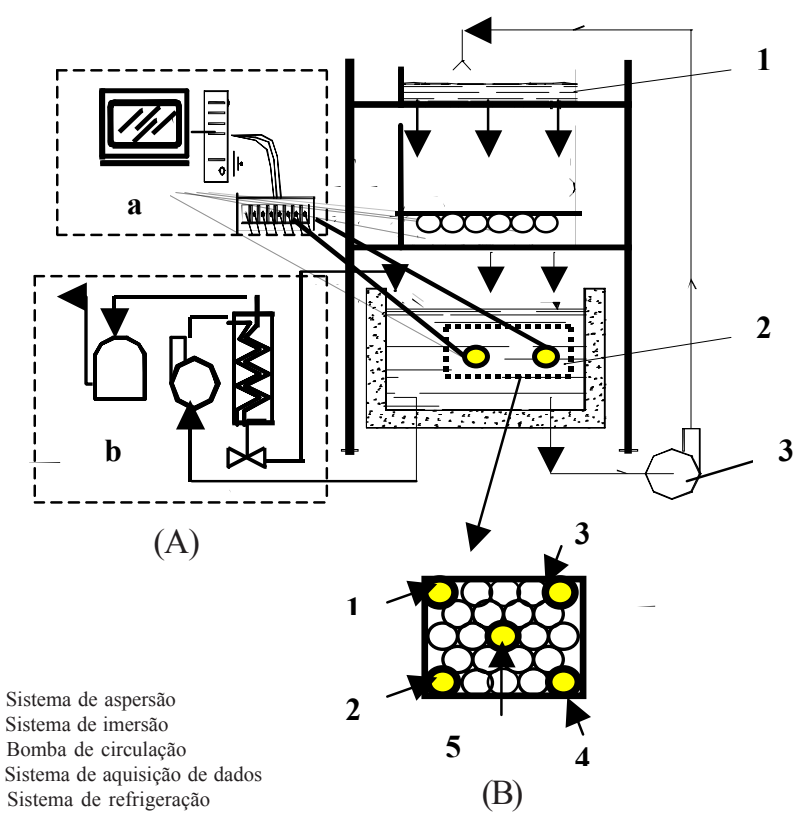

Figura 2. (A) Elementos que compõem o sistema de resfriamento com água e (B) Pontos onde foram inseridos os termopares, para a medição da temperatura

O tanque de água $(780 \times 580 \times 570 \mathrm{~mm})$ possui capacidade de $0,23 \mathrm{~m}^{3}$, com vazão de aproximadamente $0,001 \mathrm{~m}^{3} \mathrm{~s}^{-1} \mathrm{e}$ isolamento de lã de vidro $(5 \mathrm{~cm})$. Uma solução de cloro ativo foi adicionada à água do tanque (aproximadamente 150 ppm). A temperatura da água foi mantida pelo ciclo de refrigeração, a $1{ }^{\circ} \mathrm{C}$.

A temperatura dos produtos submetidos ao resfriamento foi medida usando-se termopares do tipo $\mathrm{T}$, previamente calibrados $\left( \pm 0,3{ }^{\circ} \mathrm{C}\right)$. A temperatura da água no interior do tanque também foi monitorada em dois pontos. O sistema de aquisição de dados por computador (a, na Figura 2) foi semelhante ao utilizado nos testes de resfriamento com ar forçado.

Os termopares foram inseridos no centro dos frutos (determinado a partir do raio) cinco laranjas (Figura 2B). Dois termopares foram utilizados para medir a temperatura da água de resfriamento, na tubulação de saída da água ao reservatório, e outro no seu interior. Um outro termopar foi colocado para medir a temperatura do ar exterior.

Uma caixa de laranja (com cerca de $15 \mathrm{~kg}$ ) foi utilizada para o desenvolvimento dos experimentos. Os frutos foram colocados em arranjo alternado, numa embalagem construída especialmente para o experimento ( $450 \times 300 \times 300 \mathrm{~mm})$, feita com arame em quadrículas, o que garantiu o contato adequado das frutas com a água de resfriamento no tanque.

\section{Determinação do tempo de resfriamento}

Para a determinação experimental do tempo de resfriamento foram usados os dados experimentais de temperatura lidos no centro dos frutos $(\mathrm{T}=\mathrm{Tc})$ para cada ponto em que foi monitorada a temperatura, e calculada a Taxa Adimensional de Temperatura (TAT) (ASRHAE, 1994 e Moshenin, 1980):

$$
\begin{gathered}
\mathrm{TAT}_{1 / 2}=\frac{\mathrm{Tc}-\mathrm{Ta}}{\mathrm{Ti}-\mathrm{Ta}}=0,5 \\
\mathrm{TAT}_{7 / 8}=\frac{\mathrm{Tc}-\mathrm{Ta}}{\mathrm{Ti}-\mathrm{Ta}}=0,125
\end{gathered}
$$

donde:

$$
\begin{aligned}
& \text { Tc } \quad \text { - temperatura no centro dos frutos, }{ }^{\circ} \mathrm{C} \\
& \text { Ti } \quad \text { - temperatura inicial das frutas, num instante de tempo, } \\
& { }^{\circ} \mathrm{C} \\
& \text { Ta } \quad \text { - temperatura do meio de resfriamento (ar ou água), } \\
& \quad{ }^{\circ} \mathrm{C} \\
& \text { TAT } \quad \text { - taxa adimensional de temperatura }
\end{aligned}
$$

Nos experimentos com ar forçado, Ta é igual à temperatura do ar (Tar) e nos experimentos com água gelada, Ta é igual à temperatura da água (Tag). No instante em que TAT seja igual a 0,5 , o produto terá atingido o tempo de meio resfriamento $\left(\mathrm{TAT}_{1 / 2}\right)$; quando a TAT for igual a 0,125 aproximadamente no centro, os frutos terão atingido o tempo dos sete oitavos do resfriamento $\left(\right.$ TAT $\left._{7 / 8}\right)$.

Antes do início dos experimentos, fez-se a determinação da massa e das dimensões dos frutos. Em todos os experimentos de resfriamento, realizaram-se duas repetições.

\section{RESULTADOS E DISCUSSÃO}

\section{Resfriamento com ar forçado}

A temperatura inicial média dos frutos foi de $25,2{ }^{\circ} \mathrm{C} \pm 0,2$, sendo que o tempo de meio resfriamento foi atingido quando, no centro dos frutos, a temperatura atingiu, aproximadamente, $12,8^{\circ} \mathrm{C}$ e os sete oitavos do tempo de resfriamento foi alcançado quando a temperatura atingiu $3,6{ }^{\circ} \mathrm{C}$, aproximadamente. A temperatura média exterior foi de $27,2{ }^{\circ} \mathrm{C} \pm 1,3$. As frutas apresentaram massa média de 14,04 $\pm 10,9 \mathrm{~g}$.

Entre os diferentes pontos existiu um diferencial da TAT, que refletiu no tempo de resfriamento, como mostrado na Figura 3.

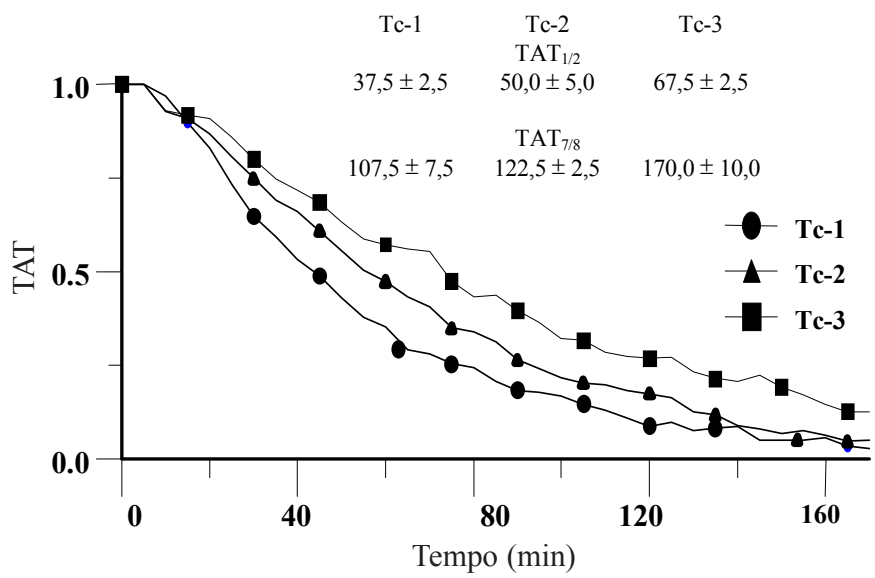

Figura 3. Curvas de resfriamento de laranja Valência num sistema com ar forçado. Tc - temperatura no centro dos frutos nas diferentes posições onde foi monitorada 
Como exemplo, observa-se que, no instante em que o ponto 1 atinge o tempo de meio resfriamento, no ponto $2 \mathrm{Tc}$ é de $15,9^{\circ} \mathrm{C}$ e, no ponto 3 de $17,5^{\circ} \mathrm{C}$. Esses valores representam uma diferença de 19 a $27 \%$ ao longo do leito (de 4,7 a $1,6^{\circ} \mathrm{C}$ ).

Este diferencial de temperatura deve ter sido provocado pela possível diminuição do escoamento do ar através dos frutos e pelo aumento da temperatura do ar de resfriamento. Vários trabalhos demonstram a existência de um diferencial de temperatura ao longo do leito (Baird et al., 1985; Novy \& Kieckbusch, 1986; Arifin \& Chau, 1987; Baird et al., 1988; Alvarez \& Letang, 1994), porém os frutos que se encontram em maior contato com o fluxo de ar, resfriam-se mais rapidamente que aqueles que se encontram numa posição mais afastada (Teruel, 2000).

Por outro lado, Talbot \& Chau (1991) resfriaram morango desde a temperatura ambiente (aproximadamente $28^{\circ} \mathrm{C}$ ) até a temperatura de $5{ }^{\circ} \mathrm{C}$. O tempo de sete oitavos do resfriamento variou em função da taxa de ar e da área de abertura das embalagens, entre 160 a 52 min (taxas de 1,04 a $6,24 \times 10^{-3} \mathrm{~m}^{3} \mathrm{~s}^{-1}$ ).

\section{Resfriamento na câmara convencional}

A temperatura média inicial dos frutos foi de $26,6{ }^{\circ} \mathrm{C} \pm 0,5$, sendo que os frutos atingiram o tempo de meio resfriamento quando o valor de $\mathrm{Tc}$ foi de aproximadamente $13{ }^{\circ} \mathrm{C}$. O tempo de sete oitavos do resfriamento (TAT ${ }_{7 / 8}$ ) foi atingido quando $\mathrm{Tc}$ foi de $3{ }^{\circ} \mathrm{C}$. A temperatura do ar exterior, durante o desenvolvimento dos experimentos foi, em média, de $26,3^{\circ} \mathrm{C} \pm 1,4$.

Comprovou-se a existência de um diferencial de temperatura entre os dois pontos escolhidos aleatoriamente no interior do leito. Esta diferença variou entre 4 e $7{ }^{\circ} \mathrm{C}$, o que refletiu no tempo de resfriamento, o qual foi diferente para cada ponto, variando entre 127,5 a 185, 0 min $\left(\mathrm{TAT}_{1 / 2}\right.$ ) e entre 362,5 a $460 \mathrm{~min}$ $\left(\mathrm{TAT}_{7 / 8}\right)$ (Figura 4$)$.

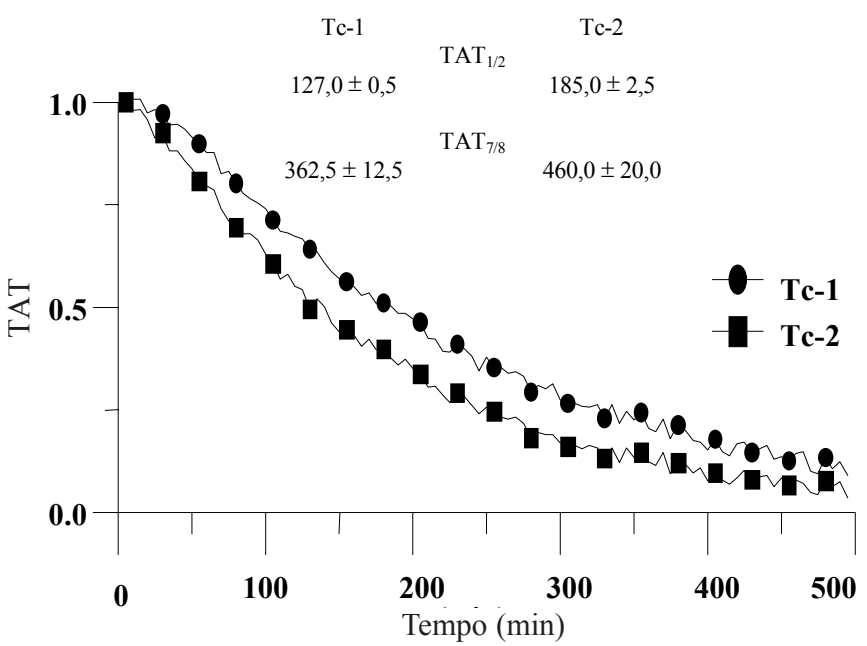

Figura 4. Curvas de resfriamento de laranja Valência no sistema convencional (câmara de estocagem). Tc- temperatura no centro dos frutos nas diferentes posições onde foi monitorada

Resultados semelhantes foram obtidos por Fraser \& Otten (1992) que determinaram o tempo de resfriamento de pêra, submetida a resfriamento numa câmara convencional e num sistema com ar forçado. Segundo os autores, o tempo de sete oitavos do resfriamento $\left(\mathrm{TAT}_{7 / 8}\right)$ foi atingido em $65 \mathrm{~min}$ no sistema com ar forçado e em aproximadamente, $285 \mathrm{~min}$ no sistema convencional, partindo de uma temperatura ambiente de até $3{ }^{\circ} \mathrm{C}$. O tempo de resfriamento foi quatro vezes maior no sistema convencional, quando comparado com o sistema de ar forçado.

\section{Resfriamento com água gelada}

A temperatura inicial do produto foi de $25,7^{\circ} \mathrm{C} \pm 1,1$, sendo que o tempo de meio resfriamento e o tempo de sete oitavos do resfriamento foram atingidos quando, no centro dos frutos, a temperatura foi de aproximadamente, 12,5 e $3,7{ }^{\circ} \mathrm{C}$, respectivamente. A temperatura do ar exterior foi de $26,3{ }^{\circ} \mathrm{C} \pm 0,9$. Os frutos apresentaram uma massa média de $235,16 \mathrm{~g} \pm 12,1$. A água se manteve numa faixa de temperatura de $1 \pm 0,7^{\circ} \mathrm{C}$.

Em alguns pontos, o valor do tempo de resfriamento foi praticamente igual entre as repetições, o que demonstra que foi possível obter-se uma reprodutibilidade adequada dos dados. Em média, o tempo de resfriamento foi de 24,5 min (TAT $1 / 2$ ) e de 57,5 min $\left(\mathrm{TAT}_{7 / 8}\right)$, para todos os frutos da caixa. O desvio padrão médio entre todos os pontos foi de, aproximadamente, $2 \mathrm{~min}$ (Figura 5).

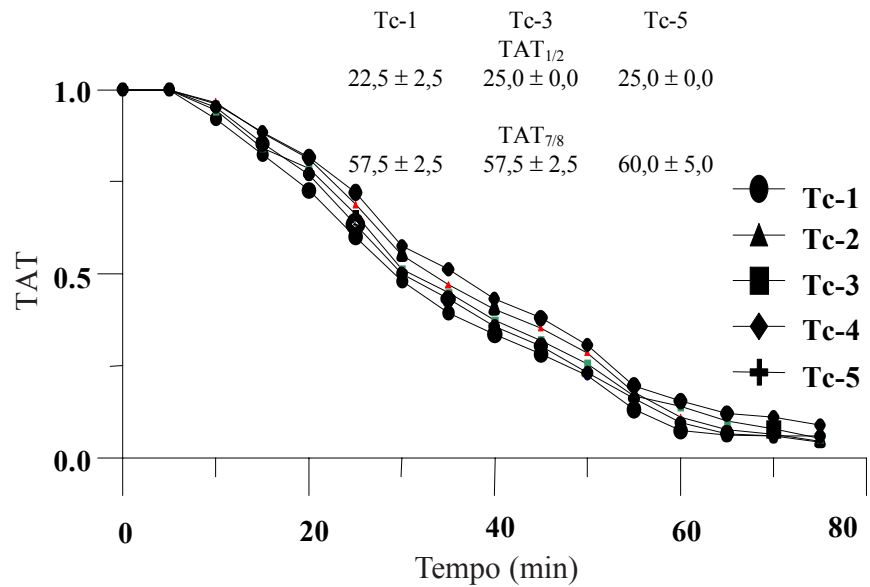

Figura 5. Curvas de resfriamento de laranja Valência no sistema com água. Tc - temperatura no centro do produto nos diferentes pontos monitorados

O baixo valor do desvio-padrão permite afirmar-se que, praticamente, não existiu diferença no tempo de resfriamento entre os diferentes pontos, o que representa homogeneidade do resfriamento entre os diferentes pontos. Por outro lado, o sistema consegue manter a temperatura da água estável, fator este de grande importância para garantir a eficiência do sistema de resfriamento com água.

Dincer \& Genceli (1994) obtiveram tempos de resfriamento em torno de $27 \mathrm{~min}$ (15 kg de pepinos) resfriados com água gelada $\left(\mathrm{Tag}=4^{\circ} \mathrm{C}\right)$ e um tempo de $47 \mathrm{~min}$, quando resfriados num sistema com ar forçado. Tempos de resfriamento entre $36 \mathrm{e}$ 54 min foram obtidos durante o resfriamento de pêssego, maçã, milho e cítricos (ASHRAE, 1994).

Goyette et al. (1997) determinaram o tempo de resfriamento de talos de brócoli submetidos a resfriamento com água gelada, a $0{ }^{\circ} \mathrm{C}$; os produtos partindo de uma temperatura inicial de $24^{\circ} \mathrm{C}$. O tempo de resfriamento variou entre 2 e $10 \mathrm{~min}$ (talos com 22 a 37 mm de diâmetro).

Diversos experimentos revelam que este tipo de resfriamento pode ser aplicado numa infinidade de produtos, como: maçã, 
laranja, tangerina, morango, aipo, couve-flor, uvas, espinafre e bananas, dentre outros (Arifin \& Chau, 1987; Ohling, 1990).

\section{Comparação dos resultados obtidos no sistema convencional,} com ar forçado e água gelada

$\mathrm{Na}$ Figura 6 apresentam-se as curvas de resfriamento obtidas a partir da média das leituras de temperatura para cada ponto em cada sistema de resfriamento.

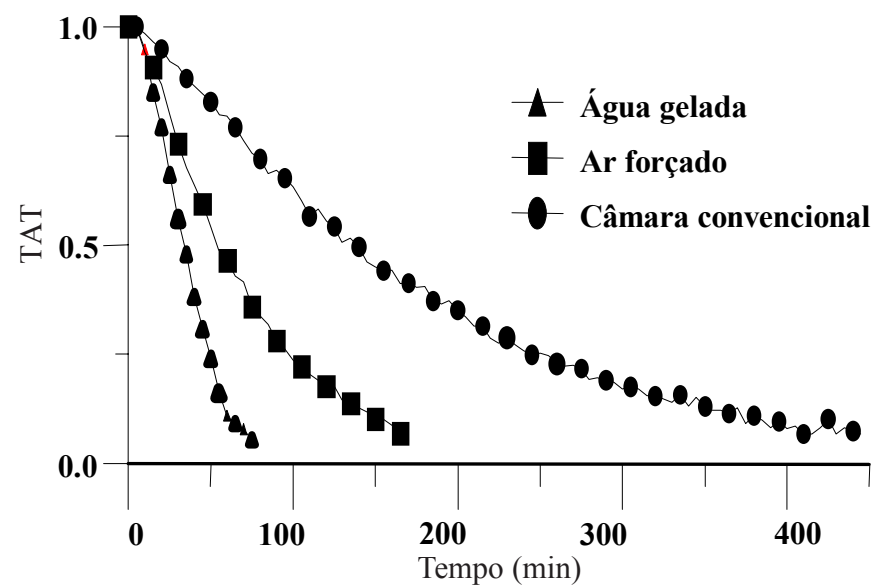

Figura 6. Curvas de resfriamento de laranja Valência no sistema convencional, com ar forçado e água

Observa-se que o tempo médio de resfriamento (referido aos 7/8 do resfriamento) foi de 412 min na câmara de estocagem, em média, 140 min no sistema com ar forçado, e de 57 min no sistema com água. Esses valores representam diferenças da ordem de $66 \%$ entre câmara convencional e ar forçado, $86 \%$ entre câmara convencional e água, e de $58 \%$ entre ar forçado e água.

Como discutido por Mitchell et al. (1973), os sistemas de resfriamento convencionais precisam de um tempo maior de até dez vezes que os sistemas com ar forçado; mesmo assim, os sistemas que utilizam água são de duas a três vezes mais rápidos que os sistemas com ar forçado. Dincer \& Genceli (1994) obtiveram tempos quase duas vezes maiores durante o resfriamento de pepino com ar forçado, quando comparado com o resfriamento num sistema com água.

Nas câmaras convencionais, o ar circula livremente pela câmara, a velocidades relativamente baixas (menores que $1 \mathrm{~m} \mathrm{~s}^{-1}$ ) sem seguir algum caminho preferencial. Nos sistemas com circulação forçada, o ar é conduzido por entre o volume de caixas, a velocidades mais altas (entre 1 a $5 \mathrm{~m} \mathrm{~s}^{-1}$ ) o que faz com que o processo de transferência de calor seja mais intenso e os tempos de resfriamento menores; mesmo assim, o tempo de resfriamento é diferente ao longo do leito, como já foi discutido.

Já nos sistemas que utilizam água como meio de resfriamento, a película de água envolve completamente todo o volume do fruto, permitindo um contato eficiente da superfície com o fruto, dando-se o processo de transferência de calor de forma muito intensa. O coeficiente de transferência de calor, parâmetro que mede a eficiência do processo de resfriamento, pode chegar a valores até seis vezes maiores, quando comparado com sistemas com ar forçado e câmaras convencionais (ASHRAE, 1994; Teruel, 2000).
Quanto menor for o tempo de resfriamento, maior será a eficiência do resfriamento. Hall (1972) comprovou que o tempo de meio resfriamento de maçãs numa câmara de estocagem foi de $22 \mathrm{~h}$ (acondicionadas em caixas) sendo que num túnel de ar forçado (velocidade de 3 a $6 \mathrm{~m} \mathrm{~s}^{-1}$ ), o tempo diminuiu para $14 \mathrm{~h}$. A temperatura inicial dos frutos era de $26^{\circ} \mathrm{C}$ e foram resfriadas a temperatura de até $5^{\circ} \mathrm{C}$.

Por outro lado, quando o resfriamento é realizado em câmaras convencionais, as quais não são adequadas ao tipo de resfriamento, o custo total de resfriamento dos produtos é maior que quando realizado o resfriamento em sistemas mais eficientes, porque a energia necessária para levar o produto até as condições requeridas, é menor (Teruel, 2000).

\section{CONCLUSÕES}

De acordo com os resultados obtidos neste trabalho, recomenda-se, para se realizar o resfriamento rápido depois da colheita e dependendo do produto em particular:

1. O uso de sistemas de resfriamento com água, seguido dos sistemas que utilizam ar forçado.

2. As câmaras convencionais devem ser usadas apenas para a estocagem e a manutenção da temperatura de resfriamento, atingida nos sistemas antes mencionados.

\section{AGRADECIMENTOS}

À Fundação de Amparo à Pesquisa do Estado de São Paulo, FAPESP, pelo apoio financeiro à pesquisa.

\section{LITERATURA CITADA}

Alvarez, G.; Letang, G. Transferts de chaleur et de matiere au sein d' un échangeur de type "palette". Revue du Froid, Paris, v.47, p.47-49, 1994.

Arifin, B.B.; Chau, K.V. Forced air cooling of strawberries. American Society of Agricultural Engineers, St. Joseph, Paper no. 87-6004, 1987. 5p.

ASHRAE - American Society of Heating, Refrigerating and Air-Conditioning Engineers. Systems and applications. Methods of precooling of fruits, vegetables and flowers. Atlanta, 1994. cap.10, p.1-10.

Baird, C.D.; Chau, K.V.; Gaffney, J.J. An engineering/economic model for evaluating forced-air cooling systems for fruits and vegetables. Refrigeration Science and Technology. Institute International of Refrigeration. New York, v.1, n.5, p.259-266. 1985.

Baird, C.D.; Gaffney, J.J.; Talbot, M.T. Design criteria for efficient and cost effective forced-air cooling systems for fruits and vegetables. ASHRAE Transactions, Atlanta, v.94, p.1434-1453, 1988.

Carraro, F.A.; Mancuso, C.M. Manual de exportação de frutas. Brasília: Ministério da Agricultura, do Abastecimento e da Reforma Agrária, Brasília, 1994. 56p.

Dincer, I.; Genceli, O.F. Cooling process and heat transfer parameters of cylindrical products cooled both in water and air. International Journal Heat Transfer, New York, v.37, n.4, p.625-633, 1994. 
Fraser H.; Otten, L. Predicting 7/8 cooling times for peaches by comparing heat transfer modelling and field measurement methods. American Society of Agricultural Engineers, St. Joseph, Paper no. 92-6016. 1992. $10 \mathrm{p}$.

Goyette, B.; Vigneault, C.; Panneton, B.; Raghavan, G.S.V. Method to evaluate temperature at the surface of horticultural crops. Canadian Agriculture Engineering, Toronto, v.38, n.4, p.291-295, 1997.

Hall, E.G. Precooling and container shipping of citrus fruits. Food Research Quality, Florida, v.32, n.1, p.1-10, 1972.

IBRAF - Instituto Brasileiro de Frutas. Boletim Informativo, Brasília, 1999. s/n, 60p.

Kader, A.A. Postharvest technology of horticultural crops. 2.ed. Oakland: Division of Agriculture and Natural Resources, University of California,1992, 295p.
Mitchell, F.G.; Guillou, R.; Parsons, R.A. Commercial cooling of fruits and vegetables: Manual Series No.43. Califórnia: Division of Agricultural Sciences. University of California, 1973, 44 p.

Mohsenin, N.N. Thermal properties of foods and agricultural materials. 2.ed. Amsterdan: Gordon and Breach Publishers, 1980, $405 \mathrm{p}$

Novy, M.; Kieckbush, T.G. Equações para o cálculo do tempo de resfriamento em leitos de frutas esféricas. Revista Ciência e Tecnologia de Alimentos, São Paulo, n.6, p.1-16, 1986.

Ohling, R.S. Rapid air precooling of fruits and vegetables. ASHRAE Journal, Atlanta, v.1, n.3, p.60-65, 1990.

Talbot, M.T.; Chau, K.V. Precooling strawberries. Institute of Food and Agricultural Sciencies. University of Florida, Florida, v.1, n.94, 8p, 1991.

Teruel, M.B.J. Estudo teórico-experimental do resfriamento com ar forçado de laranja e banana. Campinas: UNICAMP, 2000. 300 p. Tese Doutorado 